\title{
NICOLÁS DE DAMASCO Y DON JUAN VALERA. UNA FUENTE GRIEGA DE DOS RELATOS DE VALERA
}

Margarita Almela Boix

$U N E D$

La primera pieza narrativa de don Juan Valera es un cuento muy breve titulado Parsondes que, curiosamente, fue concebido por su autor como un apólogo moral. En su redacción original apareció este relato el 15 de febrero de 1859, formando parte de un artículo de la sección «Revista de Madrid» en El Estado (XLV, 23-32). Fue en 1864 cuando Valera le dio su redacción definitiva como cuento autónomo y lo publicó con el título de Cuento soñado en su tomo de Estudios críticos ${ }^{1}$. Por fin, en 1878, recibió el título con el que lo conocemos, Parsondes, al ser incluido en un volumen junto con El pájaro verde y Pasarse de listo.

Si resulta curioso que su estreno como narrador lo haga Valera tan tímidamente, cobijado por el tono ligero de un artículo de prensa, aún resulta más sorprendente que, para lo que no había de ser sino una «pieza de adorno» de un artículo periodístico, en el que este cuento entraba como un ejemplo, Valera realizara un trabajo de adaptación y reelaboración del relato de un historiador griego de segunda fila, y muy poco conocido además. Pues la historia de Parsondes que nos cuenta Valera, aunque algo transfigurada para servir mejor a sus propósitos, no es invención suya. Diodoro Sículo $\left(90\right.$ a 20 a. JC) ${ }^{2}$ y Nicolás de Damasco (n. hacia el 60-40 a. JC) son los autores que nos han transmitido

\footnotetext{
I Cfr. José Fernández Montesinos, Valera o la ficción libre, Madrid, Castalia, 1970, p. 36.

En Obras Completas de Valera, Madrid, Aguilar, 1958, vol. III, pp. 595 a 597, puede leerse la primitiva versión de Parsondes, tal como apareció en El Estado, el 15 de febrero de 1859.

2 Diodoro Sículo, II (II, 33) 33 y ss.
} 
la singular aventura de este también singular personaje. Hemos de advertir, sin embargo, que Valera no menciona a ninguno de estos historiadores ni una sola vez en toda su obra, tan cuajada, por otra parte, de referencias griegas. Podría pensarse, por tanto, que Valera ha tomado la anécdota de cualquier autor moderno que pudiera recogerla, pero las pocas - aunque significativas- variantes que su cuento presenta con respecto al texto del segundo libro de la Historia Universal, de Nicolás de Damasco, no sólo demuestran que este historiador, amigo y consejero de Herodes, y preceptor además de los hijos de Antonio y Cleopatra, es la fuente directa de Parsondes, sino que atestiguan que Valera tenía delante su texto cuando escribia el cuento.

Difícil resulta, por lo mismo que no poseemos una referencia directa a Nicolás de Damasco en toda su obra -incluida la copiosa correspondencia-, saber cuándo y cómo llegó Valera al conocimiento de este autor, pero, puesto que la temprana fecha de 1859 en que fue escrito Parsondes limita bastante las opciones de edición que pudo consultar, me inclino a creer que Valera hubo de leer el fragmento de Nicolás de Damasco en el tomo III de Fragmenta Historicorum graecorum, de C. y T. Müller, 5 vols., París, $1841-1870^{3}$.

Pero veamos en qué consiste el cuento de Valera antes de seguir adelante con Nicolás de Damasco. Contado en primera persona como experiencia propia, el cuerpo del cuento aparece enmarcado por dos momentos "reales» - la presentación y la moraleja final que se sitúan en el tiempo y espacio del autor-, como una aventura soñada que transcurre en un ambiente muy distante. Un narrador, que se identifica con el propio autor, declara al comienzo su propósito de advertir al lector contra la hipocresía farisaica de ciertos censores del día que zahieren por envidia más que por virtud y entereza de ánimo, e, inmediatamente, cede la palabra a un segundo narrador que relatará, también en primera persona, el sueño que ha de servir de ejemplo para tal propósito. Desde el primer momento, por tanto, el lector queda informado de que lo que va a leer a continuación es una versión de «desengaño en un sueño», motivo literario que se remonta en nuestra literatura hasta el cuento de «Don Illán y el Arzobispo de Santiago» - XI de El Conde Lucanor, de don Juan Manuel-, y llega, a través de La vida es sueño, de Calderón, y de Sueños hay que lecciones son y efectos del desengaño, hasta $E l$ desengaño en un sueño (1842), del Duque de Rivas; motivo que será también la clave de la última novela de Valera, Morsamor (1899). Hemos de advertir a este respecto que cada nueva narración de don Juan Valera suele tener raíces en relatos anteriores, los cuales se convierten así en embriones de ideas que su autor tratará de desarrollar en

${ }^{3}$ Coray publicó también en 1805 fragmentos de Nicolás de Damasco. 
una $o$ en varias direcciones a lo largo de su vida. Me parece, pues, inexacta la afirmación de Montesinos acerca de que Parsondes «constituye en la obra narrativa de Valera excepción en todo» ${ }^{4}$, si bien es cierto que su primitiva concepción como apólogo ilustrativo de un artículo periodístico le ha conferido ciertas peculiaridades. $Y$ tal afirmación me parece inexacta porque en Parsondes están presentes ya un buen número de los elementos temáticos que van a caracterizar los relatos de Valera hasta el final de su vida. Las recurrencias de su obra abarcan tanto a personajes como a situaciones; a fuentes de inspiración como a referencias culturales. Serán muy pocos los casos - a medida que se avanza cronológicamente en sus narraciones - en que una situación se nos presente como insolita; como es igualmente muy poco probable que una referencia cultural nueva no volvamos a encontrarla en otro relato posterior, aunque para ello debamos esperar varios años. Porque, generalmente, estas referencias culturales no son fruto de una lectura circunstancial sino la consecuencia de la asunción de tales lecturas a su propio modo de pensar, o dicho de otro modo, a su propio modo de ver y entender el mundo. $\mathrm{Si}$ existe algún narrador intelectual —en el sentido más estricto del término- en el siglo XIX español, éste es, sin duda, Valera. Como tal, contempla la realidad a través de la distancia que su filtro cultural le proporciona y ello le mueve, en muchos casos, a experimentar con situaciones posibles a partir de un planteamiento inicial dado. Pues en el sentir de Valera al novelista, o al poeta - como gustaba llamarlo y llamarse-, no le queda, para ser original en su obra, ninguna idea nueva, o no escrita, sino la forma personal de expresar las viejas ideas en múltiples combinaciones. Es evidente, pues, que esta concepción de la literatura acerca a Valera, por un lado, a los hombres del Renacimiento en lo referente al modo de entender la originalidad y la mímesis, y, por otro lado, la experimentación que esta teoría conlleva en el momento de ponerse en práctica, relaciona también a Valera con los teóricos del Naturalismo, con la sustancial diferencia de que la observación de la naturaleza se realiza siempre, por parte de nuestro autor, a través del filtro cultural de que hablábamos. antes, y de que, en su particular retorta, los elementos procedentes de esta observación de la naturaleza se mezclan y combinan con otros que provienen del acervo cultural universal. Esta constante experimentación es lo que determina que Valera vuelva una y otra vez sobre los mismos temas a lo largo de toda su vida, proyectando sobre ellos sus reflexiones y mostrando las posibilidades diversas de combinación que sus elementos poseen. $O$ de otro modo: esa sensación que se percibe de forma intuitiva de que Valera parece haber escrito una sola historia de formas diferentes a lo largo de

${ }^{4}$ Montesinos, Valera o la ficción libre, ed. cit., p. 57. 
toda su vida, es, en el fondo, una realidad cuyas causas se encuentran en su personal entendimiento de la literatura. $Y$ a esas mismas razones obedece también el hecho de que él mismo afirme insistentemente que sus obras son la exposición de un caso particular del que nunca pueden, ni deben, deducirse consecuencias, o tesis, de orden general.

En relación con esto último es, quizá, en lo único que podemos afirmar, con Montesinos, que Parsondes constituye una excepción, por su carácter de apólogo moral, expresamente declarado, como hemos visto.

Pero volvamos al hilo de la narración que nos ocupa y que, como ya dije, está relatada en forma de sueño. El cuento consiste en la aventura vivida $\longrightarrow$ soñada - por el narrador, quien, convertido en el sátrapa "más rígido, grave y moral» de la corte del gran rey Arteo de Susa, "más de dos mil seiscientos años ha», es encargado de buscar al santo varón Parsondes, desaparecido misteriosamente siete años antes. El desengaño que sufrirá este sátrapa discípulo del santo Parsondes cuando encuentre finalmente a su maestro dará pie a la moraleja del cuento, resumida en un verso de la Epístola a Claudio, de Leandro Fernández de Moratín: ¡Desdichado aquel que hace alarde de virtud sin tenerla probadísima!
¡Dichoso aquel que la practica y calla!

Fue M. ${ }^{a}$ Rosa Lida de Malkiel quien, en un artículo de 1942, mostró la dependencia del relato de Valera con respecto de la Historia Universal de Nicolás de Damasco, y en él puede leerse el texto original completo que sirvió de fuente al Parsondes s; aquí vamos a analizar las diferencias introducidas por Valera en el relato griego a fin de que éste pudiera servir de ejemplo de lo que no debe hacerse en materia de moral y de censura.

En primer lugar, el sueño del personaje de Valera comienza siete años después de la desaparición de Parsondes; es decir, tanto el lector como los personajes del cuento desconocen las causas de tal desaparición, aunque sea fácil suponerlas derivadas del odio que pudieron despertar las continuas censuras de Parsondes contra el comportamiento de Nanar, rey de Babilonia tributario de Arteo. Otros muy distintos son los antecedentes de esta historia en el texto de Nicolás de Damasco:

5 "El Parsondes de Juan Valera y la Historia Universal de Nicolao de Damascom, Revista de Filología Hispánica, IV pp. 274-281. El texto de Nicolás de Damasco que M." Rosa Lida traduce en su artículo procede de Fragmenta historicorum graecorum, Ed. C. Müller. París, 1883, tomo III, pp. 359-363. 
«En el reinado de Arteo, sucesor de Sardanápalo, rey de Asiria, era Parsondes el más famoso en Media por su valor y fortaleza, y el que más elogio recibía del rey de los persas (de quienes era originario) por su prudencia y belleza (...). Parsondes, muy irritado contra Nanaro de Babilonia, porque vestía con magnificencia, llevaba zarcillos en las orejas, andaba muy bien rasurado y era afeminado y cobarde, intentó persuadir a Arteo a que le quitara el mando y se lo diera a él.

Pero el Rey vacilaba en trastornar las leyes establecidas por Arbaces y ser injusto con Nanaro. Persondes, después de tratar de esto con Arteo dos o tres veces y escuchar la misma respuesta, se estuvo tranquilo, pero no pasó inadvertido ante Nanaro, quien, enterado de su intención, prometió grandes regalos a sus vivanderos (porque éstos siguen en gran cantidad al ejército del Rey) si apresaban a Parsondes y se lo traían» ${ }^{\circ}$.

La caracterización de Nanar, en uno y otro texto es, esencialmente, la misma, pero los motivos de su odio hacia Parsondes son, sin embargo, muy diferentes, pues muy diferente es el personaje de Parsondes que ha creado Valera. La transformación de la personalidad del protagonista en el cuento de Valera no obedece, en principio, a otra causa que la de servir a los propósitos moralizadores del cuento, y, por ello, el Parsondes de Valera no será ya un sátrapa ambicioso, sino un severo predicador; los motivos que impulsan a Nanar a procurar la desaparición de su enemigo son también, por tanto, muy diferentes en la versión de Valera. Por otro lado, el texto griego declara abiertamente desde el principio quién es el responsable de la desaparición de Parsondes - como ya hemos visto-, así como los medios de que se sirvió para llevarlo a cabo y el lugar en que el prisionero se encuentra oculto:

«Una vez, por azar, yendo Parsondes de caza, se separo del Rey y llego a un llano, no lejos de Babilonia (...) donde estaban los vivanderos aprestando las provisiones para el Rey. Al divisarlos, apretado por la sed, les pidió de beber. Ellos, gozosos de ver a Parsondes, le dieron de beber (...) y le rogaron que reposara alli (...). Parsondes, viendo hermosas mujeres, se quedo, pasó la noche alli y entre el amor y la fatiga, el sueño se apoderó de él. Los vivanderos irrumpieron en gran número, hicieron levantar a la mujer que le acompañaba, le ataron y le llevaron a Nanarox ${ }^{7}$.

En el cuento de Valera, sin embargo, tan sólo existen sospechas acerca de la culpabilidad de Nanar, y el destino sufrido por Parsondes se debate en las dudas sobre si habrá muerto a manos del rey de Babilonia o si, en su poder, padece «tormentos terribles». Así pues, cuando

6 P. 275 del artículo antes citado de Lida de Malkiel.

7 lbid. 
el sátrapa narrador se encamina hacia Babilonia encargado por Arteo de la búsqueda del santo Parsondes, ignora por completo cuál es la sorpresa que le aguarda. Pero Nicolás de Damasco, que no pretendía más que contar una historia de los persas, nos informa de que el rey Arteo está enterado de la suerte que ha corrido su sátrapa favorito cuando envía a un mensajero a Babilonia con la orden de que Nanar «dejase a un lado sus trapacerías babilonias y le remitiera inmediatamente» a Parsondes si no quería ser llevado al suplicio ${ }^{8}$. Por esta razón, el efecto que produce la aparición de Parsondes ante el enviado del rey en uno y otro relato es muy diferente: mientras que en el del historiador griego queda atenuado por el conocimiento previo de la afrenta a que ha sido sometido, en el de Valera el lector recibe el mismo sobresalto que el sátrapa virtuoso cuando encuentra a su severo maestro entre las tañedoras de Nanar con el siguiente aspecto:

«Traía pintadas las cejas de negro, azul los párpados, a fin de que brillasen más los ojos, y las mejillas cubiertas de colorete. Estaba todo perfumado, su traje era casi tan rico como el del rey; su andar, afeminado y lánguido; de sus orejas pendían zarcillos primorosos; de su garganta, un collar de perlas; ceñia su frente una guirnalda de flores: 10.

Además, Valera ha retardado esta aparición lo suficiente para que produzca el efecto deseado después de una larga y ansiosa espera, la misma que ha sufrido su buscador ${ }^{10}$, cosa que no ocurre en el relato griego, en el que el encuentro se produce el mismo día de la llegada a Babilonia del mensajero de Arteo.

Un detalle de la descripción de Parsondes -que aquí no hemos visto todavía, y que no podía estar presente en el original por la misma diferencia de intención de ambos relatos-, ha sido introducido por Valera para producir un doble efecto. Cuando Valera presenta a Parsondes de esta forma:

«Salio entonces del centro de aquella turba femenina uno que a no ser por la barba, hubiera podido confundirse con las mujeres» ",

${ }^{8}$ Cfr. p. 277 del artículo de Lida.

Obras Completas de Valera, vol. I, Madrid, Aguilar, 1968, pp. 1.052.

10 Vease el texto de Valera en Obras Completas, I, p. 1.052 de la ed. cit. Nanar aloja al sátrapa enviado por Arteo, le ofrece fiestas espléndidas durante muchos días, hasta que por fin, una noche, le muestra a Parsondes.

${ }^{11}$ O.C., I, p. 1.052 . 
crea una situación jocosa que rompe la tensión que ha precedido al encuentro, y, por otro lado, al imposibilitar la confusión del personaje con una mujer por medio del detalle de la barba, se suaviza el tono del relato original, en el que la transformación física de Parsondes es tan perfecta que el enviado de Arteo, invitado por Nanar a escoger de entre las bayaderas a una para pasar la noche, elige a Parsondes sin reconocerlo.

Tampoco podía servir al propósito de Valera de convertir la afrenta sufrida por Parsondes en un ejemplo contra los rígidos *censores del día", el final que Nicolás de Damasco le había dado: Devuelto Parsondes a presencia del rey Arteo, confiesa haber tolerado su sufrimiento con el solo fin de poder vengarse de Nanar, cosa que finalmente consigue, aunque ignoremos en qué consistió tal venganza ${ }^{12}$. En la versión de Valera, sin embargo, Parsondes se niega a regresar a su país aduciendo unos motivos que, necesariamente, han de escandalizar al fiel discípulo que ha ido en su busca, al tiempo que suponen la lección motivadora del desengaño que estábamos esperando:

«-Yo soy - me dijo- muy otro del que antes era. Vuélvete, si quieres, a Susa; pero no digas que vivo aún, para que no se escandalicen los magos, y para que sigan teniendo un ejemplo reciente de santidad a que recurrir. Nanar se vengó de mi ruda y desaliñada virtud, haciéndome prisionero y mandando que me enjabonasen y fregasen con un estropajo. Después han seguido lavándome y perfumándome dos veces al día, regalándome a pedir de boca y obligándome a estar en compañía de todas estas alegres señoritas, donde he acabado por olvidarme de Zoroastro y de mis austeras predicaciones, $y$ por convencerme de que en esta vida se ha de procurar pasarlo lo mejor posible, sin ocuparse de la vida de los otros. Cuidados ajenos matan al asno, y nadie lo es más que quien se mezcla en censurar los vicios de los otros, cuando sólo le ha faltado la ocasión para caer en ellos, o cuando, si en ellos no ha caído, se lo debe a su ignorancia, mal gusto y rustiqueza* ${ }^{13}$.

El discípulo de Parsondes despierta desengañado y convencido de que, «con menos riqueza y menos costa pueden los Nanares del día seducir a los Parsondes que zahieren su inmoralidad y sus vicios, movidos, no por caridad, sino por envidia» ${ }^{14}$.

Lo que en el relato griego era una tragedia, aquí se torna lección provechosa; lo que era en realidad una lucha por el poder, aquí resulta

12 El texto de Nicolás de Damasco concluye asi: $\star$ (...) Parsondes, empero, acechaba la oportunidad de vengarse, si podía, del eunuco y de Nanaro; la encontró y se vengó.» Apud. Lida de Malkiel, op. cit.

13 Valera, O.C., I, 1.052-53.

14 Valera, O.C., I, 1.053. 
una enseñanza jocosa; lo que era una dura afrenta merecedora de venganza, aquí se resuelve en una amable burla; lo que, en fin, era una anécdota de una Historia, aquí se ha transformado en una obra literaria. Pero tras este tono de humor y desenfado hay un mar de fondo tan serio que ni el chiste ni el carácter de farsa consiguen anular. En las palabras de Parsondes que hemos leído hay algo que va más allá de la enseñanza evangélica resumida en la sentencia de que, «quien esté libre de pecado arroje la primera piedra»; hay un pesimismo moral que más tarde Miguel de Unamuno había de convertir en tragedia agónica en su San Manuel Bueno, mártir (1930).

Tal vez si Valera se hubiese limitado a traducir a Nicolás de Damasco, cuyo relato ya es por sí mismo muy curioso, su versión, por muy bien lograda y muy a «su estilo" que fuera, no habría pasado de ser una buena versión o traducción, como lo fue la de Dafnis y Cloe, de Longo, en 1880 , pero la recreación del texto griego que ha realizado convierte al Parsondes de Valera en una obra singular - no por breve menos importante - dentro de nuestra literatura. Tal afirmación puede parecer desproporcionada y trataré, por ello, de justificarla.

La singularidad y la importancia del cuento, independientemente de su calidad artística, que indudablemente la tiene, radica en otros aspectos. En primer lugar, la rareza del texto que le sirve de fuente bastaría por sí misma para atraer la atención sobre él de quienes poseyesen algún conocimiento de historiografía griega - lo que, naturalmente no ha sido el caso común de los críticos que se han ocupado de estudiar a Valera-, pero, incluso, el artículo de $M .^{a}$ Rosa Lida que estableció la fuente de Parsondes ha pasado inadvertido o ha sido ignorado por cuantos han hablado de este cuento ${ }^{15}$. En segundo lugar, la ausencia de traducciones de la Historia Universal de Nicolás de Damasco -0 , para hablar con propiedad, de sus fragmentos conservados-, y las escasas ediciones que había disponibles hacia 1859 , revelan lo poco conocido que este autor era para los estudiosos de las letras clásicas, al tiempo que pone de manifiesto la sólida formación de Valera en esta disciplina ya por estas fechas; así como su fino juicio y agudeza se manifiestan en la elección de tal texto.

Conociendo su afición por la lengua griega ya desde su estancia en Nápoles (1847-1850) ${ }^{16}$, la cual le llevó a manifestar en 1851 su ambi-

15 Incluso ni el propio Montesinos ha notado la procedencia de la historia de Parsondes, y, evidentemente, no conocía el artículo de Lida, o, de otro modo, to habría señalado. De Parsondes se limita a decir Montesinos, además de lo que ya hemos señalado más arriba, que es un cuento volteriano (pp. 32 y 43 de op. cit) -aunque le parece necesario limitar la influencia de Voltaire sobre este y otros relatos de Valera-, y que «carece de pretensiones históricas» (p. 53 de la misma obra).

16 Véanse en O.C. de Valera, vol. III, las cartas fechadas en Italia en estos años. 
ción de dedicarse a la docencia de esta lengua en la Universidad de Granada ${ }^{17}$, no nos sorprende demasiado lo anteriormente visto, pues, si no ya en esta época, más adelante llegó a ser don Juan Valera uno de los mejores conocedores de la lengua griega en España, como lo demuestra, entre otras muchas cosas, que Marcelino Menéndez Pelayo le propusiera traducir en colaboración las tragedias de Esquilo ${ }^{18}$.

En tercer lugar, otro rasgo singular de Parsondes lo constituye el hecho de que ésta es la primera vez que un texto de tal autor griego ha sido utilizado en la literatura española $-y$ tal vez en todas las literaturas modernas- como materia novelesca; y no sólo Nicolás de Damasco, sino cualquier otro historiador griego -y mucho menos de segunda fila-, de los que tantas anécdotas y novelas en germen han transmitido a la literatura europea, no ha merecido en toda la narrativa española del siglo XIX una atención comparable. Este hecho sorprende aún más teniendo en cuenta el origen "humilde», de ejemplo en un artículo periodístico, que tuvo el Parsondes de Valera.

$Y$, por último, este cuento parece ser el primer intento de incorporar a nuestra literatura - aunque lo haga ya muy tarde- el tipo de relato que inauguró Voltaire; y tampoco esta particularidad parece haber sido notada por los críticos, no obstante haberse convertido en un cliché al hablar de Valera hacer alusión a su volterianismo. Aunque no es este el lugar indicado para ocuparnos de este rasgo, es obligado decir aquí al respecto que de Voltaire proceden en Parsondes el tono irónico, el carácter de censura contra censores, la ambientación oriental de la fábula - aunque otras muchas razones determinan en Valera la elección del mundo oriental como marco de muchas de sus narraciones, desde este primer cuento hasta su última novela acabada, Morsamor, como demuestro en otro lugar ${ }^{19}$, así como volterianos son también el distanciamiento producido mediante la fricción entre lenguaje y situación

17 Vid. carta a su madre, fechada en Lisboa el 11 de enero de 1851 , recogida por Carlos Sáenz de Tejada Benvenuti en Juan Valera, Serafin Estébanez Calderón, Madrid, ed. Moneda y Crédito, 1971, p. 108.

${ }_{18}$ El proyecto no se llevó a cabo por desidia, tal vez, del propio Valera, que dejó solo en esta empresa a Menéndez Pelayo. Véanse las cartas cruzadas entre ambos en el periodo comprendido entre el 8 de julio de 1878 y el 26 de diciembre de 1879 .

Que Menéndez Pelayo tenía en gran consideración a Valera como conocedor del griego lo demuestran además estas palabras de su carta del 28 de septiembre de 1878 , en las que, por debajo de la lisonja personal, se trasluce la admiración sincera:

«Tengo ganas de que nos veamos para hablar de Esquilo, cuya traducción no debe dejarse de la mano (...), aunque mis zurcidos parezcan mal junto a la tela de usted.. En Epistolario de Valera y Menéndez Pelayo, ed. de Miguel Artigas Ferrando y Pedro Sainz Rodriguez. Madrid, Espasa-Calpe, 1946, p. 46.

${ }_{19}$ Véase mi Tesis Doctoral, defendida en la UNED el día 13 de julio de 1986, con el título: La cultura como principio organizador del realismo de la narrativa de don Juan Valera. Inédita. 
y el anacronismo consciente. Como Voltaire, Valera ha querido mostrar la falsedad y ridiculez de un comportamiento observado trasladándolo simbólicamente a un mundo y un tiempo lejanos - pero reconocible como presente- que lo universaliza; al tiempo que tal ubicación permite una más fácil asimilación de la crítica que se lanza y una mayor complicidad del lector con la condena que se hace.

Once años después de escrito Parsondes, en 1870, comienza Valera a publicar en la Revista de España unas Leyendas del antiguo Oriente, de las que tan sólo aparecieron este año la Introducción y el comienzo de Lulú, princesa de Zabulistán. Abandonada su redacción, esta primera leyenda quedó inconclusa. Nueve años más tarde volverá a retomar el proyecto de Leyendas del antiguo Oriente en un nuevo intento, titulado Zarina, que, como la anterior, quedará reducida a su comienzo, publicado esta vez en la Ilustración Española y Americana (1880, XXIV, 31-34; 76-78).

Montesinos ha supuesto que debía de tratarse de cuentos breves, apoyándose para esta suposición, muy probablemente, en la declaración expresa del propio Valera en la Introducción de 1870:

\begin{abstract}
«No se echen a temblar nuestros lectores juzgándose amenazados de una obra interminable. (...) nosotros somos infecundos y perezosos, (...) cada una de nuestras leyendas será breve de por sí, y no entraremos en las menudencias y prolijidades en que entran y caen los que escriben novelas de tiempos más cercanos a los nuestros, como de la Edad Media o aun de época más moderna, de los cuales tiempos nada se ignora, y aun la Historia, que no tiene el recurso de imaginar, va siendo ya harto prolija y algo pesada, contándonos hasta los ápices al parecer más insignificantes (...), ¿a dónde iríamos a parar, si sobre lo histórico quisiéramos recamar, bordar y completar con la fantasía? Por esto (...) nos vamos al antiguo Oriente. Allí donde la ciencia no llega, es donde la imaginación y la poesía deben volarm 20 .
\end{abstract}

A pesar de esta declaración de principios, los fragmentos conservados de estas dos leyendas contienen mayor profusión de detalles y más descripciones minuciosas de las que cabría esperar por estas palabras - y, en el caso de Lulú, más de lo que suele ser habitual en otras narraciones de Valera.

Si hubiesen sido cuentos largos o novelas cortas es una cuestión que me parece improcedente plantear, dado que se trata de relatos inacabados en los que apenas está esbozado el argumento y no poseemos,

${ }^{20}$ Obras completas, 1, 901 . 
como en el caso de Elisa la Malagueña, por ejemplo, el esquema de los capítulos ni, como en Los cordobeses en Creta, el proyecto total.

Creo pues, conveniente, seguir llamando a Lulú, princesa de Zabulistán (1870) y a Zarina (1880), como las nombró su autor al crearlas, leyendas, aunque los modelos más o menos próximos que les haya dado pertenezcan, por lo general, y con mayor o menor precisión, al género novela: El toro Blanco, Zadig y La princesa de Babilonia, de Voltaire; La momia y La Corte de Merodac-Baladan, de Teófilo Gautier; Calirhoe, de Mauricio Sand; los Viajes de Antenor y los Viajes de Anacarsis 21.

Si dejamos a un lado tanto el prólogo general, que había de servir para todas las leyendas proyectadas, como la introducción particular a cada una de las que poseemos, las narraciones quedan reducidas a muy pocos elementos. Si de Lulú, princesa de Zabulistán, abandonada en 1870 , sólo nos quedan siete capítulos, el nuevo intento de 1880 de contarnos historias de remotos tiempos y lugares, tomando como base tradiciones literarias y míticas de Oriente, no pasó de los cuatro capítulos que componen el principio de la historia de Zarina. Con todo, el proyecto de las Leyendas del antiguo Oriente es uno de los más ambiciosos de Valera, según se desprende del prólogo o Introducción, el más extenso de cuantos haya escrito jamás Valera para una narracción suya. Este prólogo pretende algo más que explicar o justificar los relatos que se proponía escribir a continuación. Se trata de un verdadero artículo de divulgación en el que se resume - no sin cierta ironía en algunos casos-, las teorías vigentes, o en polémica en su tiempo, acerca del origen del hombre sobre la tierra, la Filosofía de la Historia, los estudios de Geología, Prehistoria, Arqueología e Historia Antigua de Oriente. Es evidente que con este prólogo el autor pretende, entre otras cosas, inducir al lector a que crea cuanto va a contarle a continuación: tanto aparato erudito no sería menester para referir simples historias de ficción por puro entretenimiento. Esta inducción realista ha de actuar directamente sobre el posible lector captando su interés $\longrightarrow$ su admiración- $y$, por tanto, su asentimiento previo a cuanto va a ir encontrando más adelante. Pero, a pesar de todo, Valera pide expresamente a sus lectores esa actitud de confianza y asentimiento a sus palabras, como si no fuera suficiente el despliegue de erudición previa que ha hecho ante él:

${ }^{21} \mathrm{Cfr}$. Obras Completas, I, 902. Los Viajes del joven Anacarsis, de J. J. Barthélemy, es un compendio de datos sobre ciencia, arte, religión, costumbres, usos, que le llevó a su autor treinta años escribirlo. Se publicó en 1788 . La segunda obra aludida por Valera es el Antenor, del alicantino Pedro Montengón y Paret (1745-1820), editada en 2 vols., en 1786. 
«Digo esto aquí para que se vea que tengo pruebas en favor de todos mis asertos, si bien las pruebas son inútiles, cuando lo sé y lo doy por seguro, merced a la inspiración» 22 .

Lo curioso, o, si se prefiere, irónico, es que Valera pida que el lector fíe más en su inspiración que en su estudio, pero es que él es consciente de que mucho de lo que va a referir es inventado - por él mismo o por los autores en quienes se inspira-, o que no concuerda totalmente con la verdad histórica - tanto más cuanto que las historias, o los historiadores, no concuerdan tampoco entre si-, y sabe que no está haciendo ciencia, o Historia, sino amena literatura ${ }^{23}$. Lo que tiene intención de escribir no son sino leyendas. A nadie engaña, por tanto, con sus falsificaciones, anacronismos o sincretismos. Lo que desea es que, una vez establecido el marco histórico de los relatos, éste quede olvidado y la atención se centre en el relato mismo, legendario o fantástico, que es, en realidad, lo que a Valera más le interesa. De ahí también el que nos diga:

«En el ínterin, el historiador, grave y concienzudo, tiene que limitarse a rastrear por indicios, en medio de mil vacilaciones, ciertos sucesos capitalísimos, dejando entre ellos inmensas oscuridades o lagunas por iluminar o por llenar. El poeta o el novelista, que es un poeta en prosa, es el único que por hoy puede llenarlas, gracias a una inspiración semidivina en que deben creer sus lectores* ${ }^{24}$.

Diez años después de escritas estas palabras, que pertenecen al prólogo general de 1870 , al empezar a escribir Zarina, en nada parece haber variado su proyecto primitivo de «suplir con la imaginación» lo que los sabios, «a fuerza de estudio, no acabaron de aclarar»: En el mismo punto nebuloso permanecen las historias «que más nos interesan y conmueven», a pesar del esfuerzo realizado por historiadores y filólogos para rehacer antiguos idiomas, traducir jeroglíficos, interpretar inscripciones, descifrar alfabetos y sacar a la luz restos olvidados. En vano se buscará en el resultado de tales esfuerzos rasgos del carácter auténtico de los personajes estudiados por el historiador o el arqueólogo, o los

22 Obras Completas, I, 913.

${ }^{23}$ Quizá se trata también de una crítica a los autores «realistas» que confunden verdad con verosimilitud. Recuérdense las protestas de Pereda, Fernán Caballero y Alarcón, cuando afirman que lo que ellos escriben paso real y verdaderamente tal y como ellos cuentan.

24 Obras completas, I, 909. 
móviles profundos de sus actos reflejados en inscripciones de tumbas y monumentos ${ }^{25}$. Esta historia externa, cada vez mejor conocida, no es la que a Valera le interesa en realidad. Lo que le atrae profundamente es la vida concreta de ciertos «personajes que, al entreverlos y percibirlos, indecisos, esfumados y como hundidos en el fondo de un mar de años», todavía le encantan y le ilusionan: « ¿Qué pena me da no conocerlos de cerca!», exclama. Así pues, el móvil de esta nueva leyenda seguirá siendo el deseo de «retraer a la vida, con el conjuro de la escritura y con la mágica evocación de la palabra, seres que ya existieron y que (le) son simpáticos» ${ }^{26}$, para su propio deleite y el de los demás. Cualquier otra intención utrascendente», extraliteraria, queda desterrada expresamente por el autor:

\begin{abstract}
«Otro escritor más profundo, o, mejor dicho, otro escritor menos somero que yo, se propondría, al escribir cualquiera de estas historias, dar una lección moral, política, religiosa o filosofica a los lectores; resolver algún problema de importancia; pero yo no me propongo nada de esto. Me propongo sólo entretenerme un rato y entretener a los demás. ¡Ojalá lo consiga!» 27.
\end{abstract}

Perdóneseme este largo preámbulo —que he creído útil para comprender mejor el relato- y ocupémonos ya de Zarina, cuya acción se desarrolla en Ecbatana, capital de la Media, unos 600 años antes de Cristo, en el «año 60 ó 70 , poco más o menos, (...) de la era llamada de Nabonasar». Pero, como ya hemos dicho antes, tan sólo cuatro capítulos de ella llegaron a publicarse, y de estos cuatro, el primero es una introducción de la que ya hemos hablado también; el segundo capítulo se dedica a centrar el período histórico —el reinado de Astibaras, o Ciaxares-, y sólo en el tercero comienza a apuntarse la historia, con la presentación del protagonista masculino, Estrianges, y el planteamiento del problema. El cuarto capítulo inicia realmente la aventura, pero se interrumpe bruscamente. En resumen, la historia que comienza a contarnos Valera es como sigue:

En la corte de Ecbatana, capital de Media, reina Astibaras - llamado Cyaxares por los historiadores griegos-, hijo de Fraortes. Entre todos los nobles de su corte destaca, por su belleza, destreza en todos los ejercicios corporales, valor en la guerra, prudencia, buen trato y riquezas, el joven Estrianges. La hija mayor del rey Astibaras, la bella y discreta Darvasastu, se enamora de Estrianges y el rey, su padre, ve

${ }^{25}$ Cfr. el capítulo I, prólogo, de Zarina, especialmente las pp. 934-935 de O.C., I.

${ }^{26}$ O.C., I, 935.

27 lbid., 935. 
con buenos ojos la boda, a la que accede Estrianges a pesar de no amar vivamente a la princesa. Con el trato y convivencia, ambos esposos fueron amándose cada día más, «aunque por parte de ella con grande amor, y por parte de él con tibieza», pues, aunque Estrianges amaba a su mujer "por encima de todas las otras mujeres conocidas y reales». este amor no le contentaba: «ansiaba lo absoluto y lo perfecto»:

«Estrianges se afanaba por revestir de forma sensible algo que fuese núcleo de luz increada y perfecta concreción de su idea; algo donde pudiera consumir la llama de amor que devoraba su alman ${ }^{2 x}$.

Y se afanaba, naturalmente, «en revestir al objeto de su amor (...) en un cuerpo imaginario de mujer hermosa».

Sin revelarlo a nadie, Estrianges se fue dedicando a la magia hasta conseguir realizar algunos viajes astrales, «buscando siempre el escondido objeto de su idea confusa». Finalmente, por este medio sobrenatural, una noche penetra en la alcoba de uuna tan bella mujer, que la imaginación jamás la había fingido tan bella». La mujer, como si notase su presencia, despierta de pronto y, sin sobresalto, pronuncia un conjuro en un idioma desconocido pero que, sin embargo, Estrianges comprende. Inmediatamente despierta en su propio lecho, al lado de la princesa Darvasastu. Inútilmente acudió una y mil veces Estrianges a los bebedizos mágicos y a los linimentos con el deseo de volver a ver a la hermosa mujer, pero, "por tales medios no volvió a verla nunca».

Con estas palabras acaba el fragmento que poseemos de Zarina, poco, pues, para poder saber cuál fuese la historia que Valera quería contarnos. Con todo hay en ella algunos elementos que nos permiten entrever la intención de su autor, aunque no completar la historia, y vamos a analizarlos. En primer lugar el personaje de Estrianges, el único medianamente dibujado en este principio de relato, guarda un estrecho parentesco con otros personajes valerianos que conocemos mejor, aunque su correlato más próximo lo encontramos en otra obra inacabada, Elisa la Malagueña (1903), de la que, en alguna medida, Zarina parece ser un primer intento frustrado.

Estrianges es joven, rico, poderoso, influyente en la corte como el archimago Arda-Viraf, raptor de Elisa. Como él visita en su intimidad por medios sobrenaturales a una joven, de la que se prenda. Como él también, profesa la religión de Zoroastro, y, lo que es más importante para poder suponer el posterior desarrollo de la historia, comparte con Arda-Viraf ciertos rasgos de carácter poco positivos. Ambos son orgu-

28 Ibid., 941. 
llosos y se creen superiores a los demás hombres. Aunque el autor no hace hincapié en ello, en el retraro que esboza de él Estrianges aparece "tan descontentadizo y tan crítico" que no encuentra un objeto digno realmente de su amor entre los seres que le rodean, y, al revelarnos el narrador parte de sus pensamientos, percibimos en él ese rasgo de orgullo y engreimiento:

"Yo consagro a mi mujer todo el amor que pudiera dar a otras mujeres:
yo soy un dechado de fidelidad; pero descubro en lo más profundo de mi
pecho un manantial abundante de cariño. el cual ella no conoce y del cual
ni ella ni nadie bebe. ¿De qué me vale este manantial? ¿Para qué esta ri-
queza de que nadie goza? Esta escondida virtud, ¿no llegará jamás a mani-
festarse?» ${ }^{4}$.

Estos pensamientos emparentan a Estrianges con Elisa la Malagueña, quien, en sus confidencias escribía:

"¿no podia ser que ese perfeccionamiento que yo me había dado, no sólo me apartase de mis semejantes, esto es, de los hombres y de las mujeres, sino que me hiciese digna de llamar la atención y de atraer las miradas de los genios, de las deidades o como quieran llamarse otras criaturas vivas e inteligentes más perfectas que nosotros y que por lo común no nos miran y nos desdeñan?" ".

Elisa, por su perfección, se considera digna de ser amada por un ser superior, y por ello recibe un desengaño y un castigo. Estrianges, por esa misma perfección, no encuentra objeto digno de su amor y se lo fabrica a su medida (recordemos que este rasgo de carácter lo comparte también Estrianges con la orgullosa Poldy, la protagonista de Garuda, - la cigüeña blanca, quien recibe, por ello, una lección).

Los procedimientos que Estrianges sigue para ponerse en comunicación con la desconocida y bella mujer en Zarina son, en esencia, los mismos que sigue Arda-Viraf en Elisa la Malagueña: desprenderse del cuerpo y viajar con el espíritu a través de ese fluido «cuya infinita virtualidad, potencia y brio los espiritus selectos logran a veces reunir» y que es el elemento ambiente en que se bañan, viven y respiran los espíritus. Para conseguir este poder, Estrianges recurre a los mismos medios mágicos de pociones y linimentos que utilizan a su vez Dióscoro y Zoe para buscar a Elisa. Por último, el ansia por «lo absoluto y lo per-

\footnotetext{
29 lbid., 940.

30 Ibid., 1.023.
} 
fecto» que atormenta a Estrianges, su «sed y apetito de algo confuso», la «llama de amor» sin objeto «que devoraba su alma», son los síntomas de la enfermedad espiritual que aqueja a tantos personajes románticos de Valera. Es el anhelo que amarga la vida del doctor Faustino y de Morsamor, está presente en el carácter de Elisa la Malagueña y de Rafaela la Generosa, y es también el rasgo que ha servido para caracterizar a Salomón en El bermejino prehistórico y al rey Tihur en Lulú, princesa de Zabulistán. El mismo error de Luis de Vargas en Pepita Jiménez consiste en poner también fuera de la realidad sus anhelos y aspiraciones. Todos estos personajes son curados de su mal o destruidos por el mismo, y esto no debemos olvidarlo.

Hemos de suponer, por otro lado, que Zarina es el nombre o apelativo de la hermosa mujer que recibe la inusual visita del espíritu de Estrianges y que, por lo tanto, había de ser la protagonista de este relato. Zarina, pues, aunque nada sepamos de ella con certeza, es una mujer que, como Elisa, es visitada por un ser «superior» que se enamora de ella. Hemos de suponer también que Estrianges no había de detenerse en la búsqueda de Zarina y que, al no conseguir hallarla por medios mágicos, había de recurrir a otros medios más prácticos. El indicio de que Estrianges había de encontrar a Zarina nos lo ofrece el autor en la última frase del fragmento que poseemos:

«Por tales medios no volvió a verla nunca.»

De otra suerte, por tanto, había de dar con ella.

Veamos ahora de quién se trata. El narrador ha presentado a la joven sin nombre, dormida en su lecho, sin ofrecer al lector más detalle de su persona que lo que ve el protagonista. Conocemos, por tanto, su belleza, descrita con tópicos que no permiten individualización ninguna.

"Su cuerpo, casi desnudo, era mórbido y gracioso y modelado con suaves curvas, aunque lleno de vigor; su tez, sonrosada y blanca; su frente, despejada y serena; carmin sus labios; sus mejillas como claveles, y su luenga cabellera, tan abundante, tan rubia y tan gentilmente rizada en ondas, que parecía envolver en parte a su dueña con manto de luz y de oron ${ }^{31}$.

« Los ojos de ella eran azules y llenos de luz, como el cielo en el medio día” ${ }^{32}$.

31 O.C., I, 943
32 lbid., 942. 
Observamos, sin embargo, ciertos rasgos en esta descripción física que pueden ayudarnos a identificarla: el cabello rubio y los ojos azules nos retratan a una mujer de raza «aria», blanca, raza a la que pertenece también Estrianges, según ha declarado antes el narrador, aunque no nos haya ofrecido su descripción física detallada. Sabemos, además, que es extranjera, pues su voz suena con «acento peregrino» en un idioma que Estrianges «no acertaba a deslindar cuál fuese» ${ }^{33}$. Finalmente, otro rasgo de la joven nos hace suponer que se trata de una mujer noble, no plebeya:

«creyó advertir asimismo (...) que en su gesto, en su actitud y en su mirada se revelaban la inteligencia y todo el brío de un noble carácter» ${ }^{\text {.4 }}$,

tópicos que sirven para caracterizar un porte aristocrático, como no podía ser menos en la protagonista de esta leyenda. Por si no bastara esto, nos confirma en su alta posición social el entorno en que aparece la joven:

«un pequeño recinto, cuyas paredes le pareció que flotaban como si fuesen de tela. Sobre enorme piel de oso, extendida en el suelo, había una limpia cama, con cubierta de púrpura* ${ }^{35}$.

El lugar geográfico en que se encuentra situado este dormitorio no se nos revela, pues que de otro modo la búsqueda de Estrianges no habría sido $\tan$ difícil. Sólo se nos dice que estaba uen medio de vastísima llanura, donde apenas había árboles, sino larga y verde hierba». Estrianges, pues, ignora dónde se encuentra el «escondido objeto de su idea confusa», pero nosotros, con los datos proporcionados por el narrador podemos suponer que se trata de una princesa escita. El paisaje, la tienda que es en realidad el «pequeño recinto» donde duerme Zarina, la piel de oso que sirve de alfombra - como en el palacio del rey Tihur en Lulú, princesa de Zabulistán-, el cabello rubio y los ojos azules de la joven, incluso su nombre, Zarina -que le suponemos-, así parecen indicarlo. A estos indicios hemos de sumar el que en páginas anteriores el narrador se haya detenido en hablarnos ampliamente de los escitas ${ }^{36}$

${ }^{33}$ Cfr. O.C., I, 942.

${ }^{34}$ O.C., I, 942.

${ }^{35}$ O.C., I, 942 . El subrayado es nuestro.

36 Cfr. O.C., I, 937-939. 
y de sus relaciones poco amistosas con los medos, a cuya nación pertenece Estrianges, criado en la lucha contra estos mismos escitas.

Con todos estos datos podemos ya suponer, sin demasiado riesgo de equivocarnos, que el orgullo Estrianges se ha enamorado, sin saberlo, de una princesa del pueblo enemigo a manos del cual murió su padre. $\mathrm{Y}$ como suponemos también, por algunos indicios de los que ya hemos hablado, que Estrianges no se detuvo en la búsqueda de la bella mujer vista por medios sobrenaturales, es fácil comprender que la historia que Valera quería contarnos era la del viaje del joven medo ario en busca de la mujer escita objeto de su amor, sus aventuras en esa búsqueda y el conflicto originado por la enemistad de los pueblos a que ambos protagonistas pertenecen.

La leyenda de Zarina presenta, pues, en principio, un planteamiento tópico de cuento tradicional -el héroe parte en busca de la joven que ha de ser su esposa-, mezclado con ingredientes de tragedia shakesperiana -enemistad de los pueblos o de las familias de los enamorados-. Un conflicto entre razas y religiones se plantea también en Garuda, o la cigüeña blanca y es allí resuelto felizmente a pesar de que, como no podía ser menos en una obra de Valera, la protagonista ha de pagar un precio por su «mediana» felicidad ${ }^{37}$. En Zarina, sin embargo, demasiados elementos apuntan hacia un final infeliz. No sólo es la sospecha, más que fundada, de que Estrianges había de recibir algún tipo de castigo lo que nos hace suponerlo, sino que el narrador insiste en ofrecer indicios de que la trama se encamina hacia un desenlace trágico $\longrightarrow$ al menos no afortunado para el protagonista-. He aquí cómo discurre éste acerca de la naturaleza del ser que le enamora:

«ahora, en el momento en que vivo yo, ¿vive o no vive también el ser que me enamora? Sin duda, vive. Pero, ¿vive con formas y en condiciones que me lo hagan asequible? ¿No puede haber pasado ya por la tierra que habitamos y estar aguardando, en el reino de las sombras, el día de la resurrección de los cuerpos? ¿No puede ser que aún no haya venido a esta mansión terrena y exista sólo su feruer, esto es, su esencia celestial y divina? ¿Qué esperanza me resta, si el objeto de mi amor es feruer o espíritu desprendido ya del cuerpo?» ${ }^{38}$.

Estas palabras nos hacen pensar inmediatamente en el cuento «árabe o persa» referido por Valera en Garuda, o la cigüeña blanca (1896), «donde un príncipe musulmán, que vivió doscientos o trescientos años después de Mahoma, está perdidamente enamorado de

${ }^{37}$ Cfr. el capítulo dedicado a este cuento en mi Tesis Doctoral, antes citada, pp. 168-202.

38 O.C., I, 941. 
cierta reina o infanta de Serendib o de Saba, que floreció en tiempos de Salomón y fue rival de la Sulamita», y cuyo retrato había hallado en el tesoro de su padre ${ }^{39}$. Pero, de haber pretendido Valera ofrecernos una versión de este cuento que Goethe ejemplificó en los amores de Fausto y Helena, creemos que la historia se hubiera planteado de otro modo. Sea como fuere, parece que las dudas planteadas por Estrianges acerca de la naturaleza fantasmagórica de la joven a quien ama no son sino un ingrediente que contribuye a acentuar la intriga y a predisponer al lector para la aceptación de la no consecución del objeto amado por parte de Estrianges, aunque no sean un indicador real de la identidad de la protagonista.

Cierto es que el breve fragmento de Zarina que dejó escrito Valera no permite asegurar cuál habia de ser el desenlace de la historia, y se nos podría acusar, a pesar de los indicios que hemos presentado, de aplicar un puro posibilismo en el análisis del texto que estamos realizando. Pero, si Lulú, princesa de Zabulistán, la primera de las Leyendas del antiguo Oriente, no era totalmente de su invención, como he demostrado en otro lugar ${ }^{40}$, en este caso cabía pensar que tampoco lo fuese. Y así es efectivamente. Valera conocía muy bien el final de su historia antes de comenzar a escribirla, puesto que la había leído en la Historia Universal de Nicolás de Damasco, lo mismo que ocurriera ventiún años antes con la de Parsondes. He aquí el novelesco relato que nos ha dejado el historiador griego:

«Estriangeo, después de la muerte de Marmareo, el rey de los sacos, estuvo largo tiempo enamorado de Zarinea en silencio, y ella de él. Y en una ocasión en que el hombre estuvo cerca de la ciudad de Roxánace, donde se hallaba el palacio real de los sacos, Zarinea le salió al encuentro y, tras contemplarlo con gran agrado, le dio la mano y lo besó a la vista de todos; lo subió a su carro y se dirigieron charlando al palacio real. Zarinea acogió también al ejército que lo acompañaba con todo esplendor. Después de esto, Estriangeo se retiró a su alojamiento suspirando por el amor de Zarinea, y, no pudiendo contenerse, hizo partícipe de su pena al más fiel de los eunucos que lo acompañaban. Este le daba ánimos y le exhortaba a que, arrojando lejos tan gran desánimo, le hablase a la propia Zarinea. Estriangeo, persuadido por el eunuco, se encaminó con premura entonces al lado de ella. Esta lo acogió con agrado, y él, después de mil vacilaciones, suspiros y cambios de color, se atrevió y le dijo que por un vehemente amor ardia en deseos de ella. Pero Zarinea, tras rechazarlo con gran suavidad, dijo que para ella el asunto era vergonzoso y molesto, y mucho más lo era para él, puesto que tenía por mujer a Ratea, la hija de Astibaras, la cual, sabía de oídas, era mucho más bella que ella y que muchas otras mujeres. Era preciso, pues, que él actuase como un hombre no sólo ante los enemigos sino también en tales circunstancias, puesto que así convenía, y no

${ }^{39}$ Cfr. O.C., I, 1.191.

40 Cr. mi Tesis Doctoral, pp. 328-345. 
que, por un placer corto que, además, podía conseguirlo de una concubina, arrastrase largo tiempo un pesar, si Ratea se enteraba. Al despedirse, Zarinea le dijo que le pidiese cualquier otra cosa, pues nada dejaría de obtener de su parte. Estriangeo, después de decir aquélla tales cosas, pareció quedarse en gran medida tranquilo, pero tras besarla de nuevo se alejó y se sumió en un mayor desaliento, lamentándose al lado de su eunuco. Al fin, escribió una carta en una piel e hizo jurar al eunuco que, una vez él se hubiese dado muerte, la entregase a Zarinea sin decir nada antes. Y escribió en ella: «Estriangeo dice a Zarinea lo que sigue: Yo te salve y soy el responsable de tu bienestar presente, pero tú me has matado y me has quitado la esperanza de gozar. Si esto ha sido un trato justo para conmigo, ¡ojalá encuentres todos los bienes y seas dichosa!; pero si ha sido injusto, ¡ojalá experimentes el mismo sufrimiento que yo, pues me condujiste a tal estado! » Tras escribir esto, colocó la carta bajo la almohada y pidió la espada para encaminarse virilmente hacia el Hadesw ${ }^{41}$.

Podemos afirmar con seguridad que Valera conocía este texto de Nicolás de Damasco al menos desde 1859 y que, tal vez, desde que escribiera el Parsondes tenía la intención de novelar esta historia. Es también casi seguro que había leído este otro fragmento de Ctesias acerca de la misma historia:

«Zarinea: Esta, al morir su primer marido y su hermano Cidreo, rey de los sacos, se casó con Mármero, soberano de la región de los partos. Cuando el rey de los persas se levantó en guerra, ella intervino en la batalla y, herida, huyó. Perseguida por Estriangeo, suplić́ y consiguió quedar sana y salva. No mucho después su marido hizo prisionero a aquél y quería matarlo. Ella pidió que fuera salvado y, al no poder conseguirlo de su esposo, liberó a algunos prisioneros y con su ayuda mató a Mármero, y, tras entregar la región al Persa, trabó amistad con él» ${ }^{42}$.

$\mathrm{E}$, incluso, aunque no podamos tampoco afirmarlo con total seguridad, debía de conocer Valera un tercer texto, este de Diodoro Sículo -II, $34-{ }^{43}$, basado en el anterior:

41 Nicolás de Damasco, Historias, fr. 5. FGr H, vol. II A, núm. 90, pp. 335-336. Doy las gracias a José María Lucas de Dios, quien tuvo la amabilidad de traducir para mí este texto, al igual que los fragmentos de Ctesias que refieren la historia de Zarinea y Estriangeo. También debo a su ayuda la localización del texto sobre el mismo asunto de Diodoro Sículo.

${ }^{42}$ Ctesias, Sobre Persia, fr. 7. (Jacoby, Die Fragmente der Griechischen Historischen, vol. $3 \mathrm{C}, \mathrm{n}{ }^{\circ}$ 688, pp. 451-52) Fuente: Anónimo, De mulieribus in bello claris 2).

${ }^{43}$ El texto que sin embargo no pudo conocer Valera es este otro de Ctesias, puesto que se halla en el Papiro de Oxirrinco número 2.330 (s. II d. C.), Londres. 1954: «... Y él dijo: “Ea, pues, en primer lugar escribiré una carta a Zarinea”." Y escribe: «Estriangeo a Zarina así habla: Yo te salvé y tú quedaste viva por mi intervención. mientras que yo he muerto por tu causa y yo mismo me doy muerte, ya que no has querido concederme tus 
*After the death of Artaeus, Ctesias continues, Artynes ruled over the Medes for twenty-two years, and Astibaras for forty. During the reign of the latter the Parthiens revolted from the Medes and entrusted both their country and their city to the hands of the Sacae. This led to a war between the Sacae and the Medes, which lasted many year, and after no small number of battles and the loss of many lives on both sides, they finally agreed to peace on the folloeing terms, that the Parthians should be subject to the Medes, but that both peoples should retain their former possessions and be friends and allies for ever.

At that time the Sacae were ruled by a woman named Zarina, who was devoted to warfare and was in daring and efficiency by far the foremost of the women of the Sacae. Now this people, in general, have courageous women who share with their husbands the dangers of war, but she, it is said, was the most conspicuous of them all for her beauty and remarkable as well in respect to both her designs and whatever she undertook. For she subdued such of the neighbouring barbarian peoples as had become proud because of their boldness and were tryng to enslave the people of the Sacae, and into much of her own realm she introduced civilized life, founded not a few cities, and, in a word, made the life of her people happier. Consequently her countrymen after her death, in gratitude for her benefactions and in remembrance of her virtues, built her a tomb which was far the largest of any in their land; for they erected a triangular pyramid, making the length of each side three stades and the height one stade, and bringing it to a point at the top; and on the tomb they also placed a colosal gilded statue of her and accorded her honours belonging to heroes, and all the other honours they bestowed upon her were moro magnificent than those which had fallen to the lot of ther encestors."

La leyenda que se recoge en todos estos textos era la que Valera se proponía novelar a su modo. Observemos que en el relato de Nicolás de Damasco se nos dice que Estriangeo estaba enamorado de Zarinea, aunque no se nos informa de cómo la ha conocido, lo que, sin duda, sugirió a Valera la posibilidad de inventar los fantásticos antecedentes de esta historia que ya hemos visto. Por su parte, el texto de Ctesias ofrece un encuentro en plena batalla, de los dos protagonistas, en donde Estriangeo perdona la vida a Zarinea, lo que, sin duda, debió parecerle a Valera muy sugerente y novelesco y le permitía, sin faltar a la "verdad histórica», planear un «nuevo» encuentro entre sus dos protagonistas. Este nuevo encuentro, sin duda, sería el momento en que Estriangeo reconocería a su bella y desconocida amada como a su ene-

favores. No fui yo quien escogio estas desgracias y este amor, sino que es el dios que compartes tú y todos los hombres. $Y$ así a aquel a quien se acerca propicio, le proporciona deleites sinnúmero, sin contar con que ya le haya proporcionado otros favores; pero a aquel a quien se acerca irritado, como a mí ahora, tras causarle desgracias sinfín, a la postre lo destruye de raíz y lo derrumba. Doy testimonio con mi propia muerte. Ninguna maldición lanzaré sobre ti, sino que te suplicaré la súplica más justa: si tú te has portado justamente conmigo* (Ctesias, Sobre Persia, fr. 8b) (FGr $H$, vol. III c, n. ${ }^{\circ} 688$, pp. $453-$ 54). 
miga irreconciliable. Que le perdonara la vida en una situación paralela a la que presenta Ctesias, o que ocurriese cualquier otra novelesca circunstancia es algo que en realidad importa poco. Que, agradecida, si no enamorada, Zarina devolviese a Estriangeo el favor de su vida, aunque para ello tuviera que traicionar a los suyos, como una nueva $\mathrm{Me}$ dea, podría muy bien ser un ingrediente que Valera pensara también aprovechar para su leyenda, pero lo cierto es que nada de esto podemos afirmar con seguridad a la vista del fragmento que poseemos de Zarina.

Cabría, sin embargo, preguntarse por qué no la acabó si realmente la tela estaba tejida. Podría pensarse que fue sólo pura desgana lo que le impidió acabar la obra comenzada, o, simplemente, que no le satisfacían los cuatro capítulos de ella ya publicados. Pero no nos parecen respuestas adecuadas. Valera ha elegido, como en otras ocasiones, una historia que le venía dada, y cuyo tema le atrae: una historia de desamor y suicidio, varias veces abordada, por cierto, a lo largo de su vida. No sé hasta qué punto es lícito suponer que en esta ocasión lo que Valera deseaba era dar otro final, u otro desarrollo, a la historia de $\mathrm{Ni}$ colás de Damasco que, como hemos visto, acaba con un Estriangeo que se encamina al suicidio, después de escribir una carta en que culpa a Zarinea de su muerte. La no consumación expresa de tal acto pudo, quizá, sugerir a Valera la posibilidad de otro desenlace, pero, tal vez, no lo encontró y no supo, o no quiso, terminar su leyenda. El fragmento de Zarina no nos permite eventurar más allá de lo que hemos expuesto. De lo que sí podemos estar seguros es de que, para Valera, los protagonistas de esta historia eran de esos «que se fijan en nuestra mente de un modo indeleble», invitando «a buscarlos en la fantasía y hasta en sueños, a fin de completar y acabar la historia de su vida» ${ }^{44}$.

4 O.C., I, 902 . 